\title{
POLYNOMIAL MATRICES WITH HERMITIAN COEFFICIENTS AND A GENERALIZATION OF THE ENESTRÖM-KAKEYA THEOREM
}

\author{
HARALD K. WIMMER
}

Abstract. Polynomial matrices $G(z)=I z^{m}-\sum C_{i} z^{i}$ with hermitian coefficients $C_{i}$ are studied. The assumption $\sum\left|C_{i}\right| \leqslant I$ implies that the characteristic values of $G(z)$ lie in the closed unit disc. The characteristic values of modulus one are roots of unity. An extension of the EneströmKakeya theorem is proved and a stability criterion for a system of difference equations is given.

Mathematics subject classification (2000): 15A33, 15A24, 15A57, 26C10, 30C15, 39A11.

Key words and phrases: Polynomial matrices, zeros of polynomials, root location, roots of unity, Eneström-Kakeya theorem, system of difference equations.

\section{REFERENCES}

[1] N. Anderson, E. B. SAFF, AND R. S. VARGA, On the Eneström-Kakeya theorem and its sharpness, Linear Algebra Appl. 28, 5-16 (1979).

[2] H. BAUMGÄRTEL, Analytic Perturbation Theory for Matrices and Operators, Operator Theory, Advances and Applications, Vol. 15, Birkhäuser, Basel, 1985.

[3] P. Borwein And T. ERdèlyi, Polynomials and Polynomial Inequalities, Springer-Verlag, New York, 1995.

[4] G. DIRR AND H. K. WIMMER, An Eneström-Kakeya theorem for hermitian polynomial matrices, IEEE Trans. Automat. Control 52, 2151-2153 (2007).

[5] T. FURUTA AND M. NAKAMURA, An operator version of the Eneström-Kakeya theorem, Mathem. Jap. 37, 459-497 (1992).

[6] I. Gohberg, P. Lancaster And L. Rodman, Matrix Polynomials, Academic Press, New York, 1982.

[7] A. Hurwitz, Über einen Satz des Herrn Kakeya, Tôhoku Math. J. 4, $89-93$ (1913); in: Mathematische Werke von A. Hurwitz, 2. Band, 627-631, Birkhäuser, Basel, 1933.

[8] B. LEMMENS AND O. VAN GAANS, Iteration of linear p -norm nonexpansive maps, Linear Algebra Appl. 371, 265-276 (2003).

[9] A. M. Ostrowski, Solutions of Equations in Euclidean and Banach Spaces, Academic Press, New York, 1973.

[10] V. V. Prasolov, Polynomials, Algorithms and Computation in Mathematics, Vol. 11, Springer, New York, 2004.

[11] Q. I. RAhMAn And G. SchmeISSER, Analytic Theory of Polynomials, Oxford University Press, Oxford, 2002.

[12] H. SCHNEIDER, A remark on a paper of Lemmens and Van Gaans, private communication, Moscow, 2006.

[13] H. K. WIMMER, Discrete-time stability of a class of hermitian polynomial matrices with positive semidefinite coefficients, to appear in Matrix Methods: Theory and Algorithms, V. Olshevsky and E. Tyrtyshnikov, Editors, to be published by World Scientific. 